\title{
Research on the Response Mechanism of Public Emergencies Based on Knowledge Management
}

\author{
Hang $\mathrm{Gao}^{1, *}$
}

\begin{abstract}
${ }^{1}$ Business School, Shandong University of Political Science and Law, Jinan, Shandong, China
*Corresponding author. Email: gaohang@sdupsl.edu.cn
\end{abstract}

\begin{abstract}
Information is the carrier of knowledge, and the occurrence of public emergency is accompanied by massive information. The complexity of public emergencies requires the application of a great deal of knowledge in the process of emergency warning, handling and dealing with the aftermath. This paper puts forward the concept and characteristics of knowledge management in public emergencies, and systematically analyzes the knowledge and knowledge activities in the process of emergency management. This paper also describes and classifies stakeholders in knowledge management, and establishes an emergency knowledge management system including preparation knowledge, early warning knowledge, disposal knowledge and assessment knowledge. Finally, based on the theory of knowledge management, this paper puts forward the corresponding countermeasures to the government's emergency decision-making in public emergencies.
\end{abstract}

Keywords: knowledge management, public emergencies, emergency knowledge, emergency management,

knowledge system

\section{INTRODUCTION}

In recent years, with the rapid development of economic globalization and information technology, people flow more and more frequently. At the same time, natural disasters, environmental pollution and a series of incidents affecting public safety are also increasing, making the outbreak of public emergencies continue unabated. These public emergencies pose a serious threat to human health and life safety and are likely to cause serious harm to social stability.

When faced with public emergencies, policy makers need to make effective emergency decisions in a timely manner. This requires quick access to the knowledge needed to manage public emergencies. However, the knowledge of government decision makers is generally dispersed and their ability to process information is limited. Moreover, it is restricted by its own cognitive model and current crisis environment. As a result, the ability of government policy makers to make decisions is greatly limited. This paper introduces the theories and methods related to knowledge management into the emergency decision-making of public emergencies, and makes clear the kinds of knowledge needed to deal with public emergencies. This paper puts forward a series of suggestions to enhance the knowledge management in emergency decision-making in order to further improve

*Fund: This study is funded by youth academic innovation team of management science and engineering of SDUPSL. the emergency management level of public emergencies from the perspective of strengthening knowledge management.

\section{OVERVIEW OF KNOWLEDGE MANAGEMENT IN PUBLIC EMERGENCIES}

The objects of knowledge management are divided into two levels: macro and micro. Micro knowledge management is mainly aimed at enterprises and various kinds of alliance organizations, including network organizations such as enterprises, universities and research institutes, supply chains, industrial clusters and virtual organizations. Micro knowledge management system is an organic part of macro knowledge management system.

Emergency management of public emergencies is a systematic project, which is a complex integrated system integrating disaster system, emergency organization system, logistics system, management information system and social system. In the process of emergency management, the various stages of public emergencies such as early warning, emergency response and post-disaster recovery are accompanied by various kinds of information and knowledge. Emergency knowledge management system refers to the system composed of knowledge and knowledge activities in the process of emergency management before and after the occurrence of public emergencies. Among them, knowledge includes all kinds of 
knowledge identified, acquired and shared by all subjects in public emergencies.

\section{CHARACTERISTICS OF KNOWLEDGE MANAGEMENT OF PUBLIC EMERGENCIES}

\section{A. Multi-subjectivity}

The response to public emergencies has typical complex system characteristics. After the occurrence of public emergencies, with massive information and complex and changeable environment, emergency management requires the unified organization and coordination of relevant departments. This involves most government departments and the entities under their jurisdiction. The main body of emergency management knowledge system is emergency organizations and personnel, including government, enterprises, social organizations and so on. There are great differences in the amount and structure of knowledge owned by each subject, as well as in the form of existence and sharing of knowledge within and between organizations.

\section{B. Dynamic and open}

In the knowledge management system of public emergencies, the knowledge subjects acquire and disseminate knowledge to realize knowledge sharing and application. This process produces a large amount of knowledge flow, each knowledge element is constantly changing. The knowledge system is also an open and complex system that keeps in touch with the external environment. It interacts with environmental change. The speed and degree of environmental change will cause the dynamic change of knowledge system, and the system and environment carry out various forms of knowledge exchange.

\section{Self-organization}

The knowledge management system of public emergencies has self-organization conditions. With the occurrence and development of public emergencies, the emergency information in the knowledge management system gradually forms an orderly knowledge increment from the disordered and relatively cluttered state. At the same time, the knowledge subjects in the knowledge management system are constantly increasing and updating their knowledge through internal and external feedback and learning. It also realizes the transformation of its own knowledge from the initial disordered state to the orderly stable state.

\section{Synergy}

The coordination of knowledge management system for public emergencies includes organizational synergy, resource synergy, information synergy and process synergy. Its essence is the problem of knowledge coordination. Knowledge management system establishes knowledge subject and knowledge interrelation through all kinds of knowledge gathering. This can promote the mutual cooperation among the emergency subjects, the sharing and cooperation of knowledge, and finally realize the application and innovation of knowledge.

\section{MAIN STAKEHOLDERS OF THE KNOWLEDGE MANAGEMENT SYSTEM IN PUBLIC EMERGENCIES}

The formation and operation of knowledge management system should focus on people and organizations. Stakeholders in knowledge management systems refer to individuals and organizations involved in the emergency management process. Stakeholders can be divided into four types of knowledge groups according to their roles in the emergency management process.

\section{A. Decision makers}

Emergency management offices or emergency command centers are the most common forms. They are mainly based on the scale of public emergencies by government agencies and experts in related fields, and are the core of knowledge subjects in the system. It establishes the emergency response plan, prepares the emergency response plan, and forms the important architectural knowledge needed for emergency management. In addition, through knowledge sharing with government departments and other participants, they master a large amount of knowledge and information about the occurrence and development of public emergencies. They play an important role in the emergency management knowledge system by controlling and making decisions on the flow of knowledge and maintaining close cooperation among all parties.

\section{B. Participants}

Participants refer to all levels of emergency departments involved in emergency rescue, such as public security, fire, water conservancy, transportation, meteorology, medical departments, etc. The participants are the main providers of professional knowledge in the knowledge management system. They communicate with the decision makers in the process of dealing with public emergencies. The scope of knowledge exchange includes explicit and implicit knowledge such as emergency rescue knowledge, personnel organization knowledge and cooperation and communication knowledge. The knowledge provided by the participants is an important source of decision-making knowledge acquisition, thus forming a number of twoway interactive knowledge chains. 


\section{Emergency resource suppliers}

They are individuals, groups and organizations that provide materials, equipment and other rescue and relief resources in the emergency management process of public emergencies. Emergency relief equipment mainly includes food and medicine, communication equipment, testing equipment, anti-toxic and explosionproof appliances, construction machinery, bedding and clothing tents and other supplies. The emergency command center should do a good job in the storage and information research of the relief materials, understand the types, quantities and other knowledge of the material storage, and establish contact with the suppliers in case of emergency relief materials.

\section{Media and the public}

In the internet society, the ways and channels of information dissemination are increasing, and the spread of rumors is also increasing. In active disaster relief and management, standard, real-time and correct reporting is also a problem that should not be ignored. After the occurrence of public emergencies, the government and the media become partners. Through effective communication and cooperation, the media will publicize the disaster information, report the disaster correctly, and report the most authentic and comprehensive situation to the public. Therefore, the relationship between the media and the government, the media and the public as well as the rights and obligations should be regulated to facilitate the management of the event.

\section{PROBLEMS IN KNOWLEDGE MANAGEMENT OF PUBLIC EMERGENCIES}

\section{A. Strong administrative atmosphere}

At present, in China's emergency management work, the administrative atmosphere is strong, and professional is insufficient. The participation of social forces, such as scientific research units, nongovernmental organizations and volunteers, has not been valued. In the rescue work of many public emergencies, volunteers are bursting with energy and enthusiasm. However, due to the lack of effective organization, many problems also stand out. At present, in the emergency management of public emergencies, the government should play a major role, which has been clearly defined by laws and regulations. However, on how to mobilize community forces and the masses to carry out the work of self-help and mutual aid, the government often only put forward a principled call. It is insufficient to organize non-governmental forces to participate in the institutional arrangement of emergency management of public emergencies.

\section{B. Inadequate emergency knowledge preparation}

Some organizations believe that emergencies are low-frequency events, and they pay insufficient attention to the knowledge of learning to deal with crises, which leads to a certain knowledge gap in the organization. There are many gaps in the knowledge of public emergency preparedness, early warning, response and rescue, as well as the knowledge of postcrisis assessment and recovery. Taking the fire disaster as an example, how to divide the scene warning area and how to restore the scene after the rescue, all of these require the knowledge of authoritative operating rules. In case of major public emergencies such as earthquake, fire and terrorist attacks, it is necessary to assess the disaster situation and the general death toll within 24 hours and form a disaster assessment report. This is helpful for timely implementation of rescue decisions. The basic work seems simple, but the amount of work is huge. This requires a long-term survey, statistics and research on local population, geographic information, architectural data and other information. Therefore, in order to narrow the knowledge gap and ensure the success of crisis management, organizations need to learn crisis knowledge that they do not know and increase the knowledge reserve to deal with various emergencies.

\section{Lack of relevant emergency knowledge training}

First of all, some local governments are very lack of emergency awareness, emergency management knowledge training has not been included in the management schedule of some governments. Some local governments even lack the awareness of precaution and only deal with the aftermath. Secondly, when public emergencies such as fire, earthquake and rainstorm come, citizens have a weak sense of emergency, lack of emergency knowledge, and low self-rescue ability. On the one hand, for a long time, the government lacks the awareness education for citizens to respond to public emergencies, which leads to the lack of disaster prevention awareness. On the other hand, the public opinion propaganda is insufficient, the citizen emergency training and so on still stay in the surface, even just slogan propaganda.

\section{Imperfect knowledge warning system}

Firstly, the early warning ability of serious natural disasters is not strong, and the accuracy of early warning needs to be improved. For example, in the case of severe rainstorms in many places, the weather service has not issued a high enough level of warning and insufficient warning of danger. As a result, some citizens are not aware of the dangers brought by the heavy rain, and still go out in the rain, resulting in the ultimate death and a series of consequences. Secondly, the way of early warning is backward. In many public emergencies, some places have exposed the problem of 
too few public service lines and poor connection. As a result, people cannot get information about relevant events in time. At present, microblog and other "we media" are being widely used by people. This kind of use is more important for personnel communication and information sharing after the occurrence of public emergencies. However, as a better channel for early warning, the current use of local governments is not in place.

\section{E. Less knowledge sharing}

At present, although every city has established an emergency management information system, many local governments have also established an emergency knowledge management system for different public emergencies. However, due to the lack of connectivity between these systems, their data cannot be effectively shared and utilized across departments and regions. In addition, from the perspective of emergency information transmission, it is difficult to realize rapid and effective emergency information transmission through the traditional administrative communication mode of uploading and transmitting and hierarchical transmission.

\section{CONSTRUCTION OF KNOWLEDGE MANAGEMENT SYSTEM FOR RESPONDING TO PUBLIC EMERGENCIES}

\section{A. Process of knowledge management system for public emergencies}

The occurrence of public emergencies usually follows a specific life cycle. Moreover, different countermeasures and knowledge management activities should be carried out in each life cycle stage. Based on the characteristics and actual situations of public emergencies, this paper divides the emergency management process of public emergencies into four main stages: emergency preparedness, monitoring and warning, emergency response, response termination and evaluation. Due to the rapid evolution of public emergencies, there is no clear boundary between the stages. Each stage is independent of each other and built on top of the previous stage, and contains each other's key elements and goals. Different stages are interrelated and interwoven to form a specific process system for emergency management of public emergencies.

The process of knowledge management in response to public emergencies is closely related to the process of emergency management. Before and after the occurrence of public emergencies, the whole process contains knowledge and its flow, which is reflected in a series of knowledge management activities. Corresponding to the basic process of emergency management, the basic process of knowledge management is divided into knowledge integration and classification, acquisition and sharing, application and innovation, update and storage. These four processes are also cyclic, which are perfected and improved in the continuous application of knowledge.

\section{B. Components of knowledge management system for responding to public emergencies}

The overall goal of building a knowledge management system to deal with public emergencies is to dynamically manage the relevant knowledge in each stage of the emergency process through knowledge management methods and techniques. This can improve the organization's emergency knowledge management ability and ensure the efficient implementation of emergency management. According to the four stages of the life cycle of emergency management of public emergencies and the corresponding knowledge management process, this paper constructs a knowledge management system for emergency management.

1) Knowledge system of emergency preparedness: The knowledge system of emergency preparedness mainly includes the specification of working documents and emergency plans and schemes. Work normative documents refer to the relevant laws and regulations, work plans and documents of higher administrative competent departments related to public emergencies. The construction of the emergency plan system is an important direction of the construction of the emergency mechanism for public emergencies in China, which consists of special plan, departmental plan, single plan and several local plans. A perfect knowledge system of emergency preparedness is an important guarantee to improve the ability to deal with public emergencies.

2) Knowledge system of emergency warning: The knowledge system of early warning mainly includes the knowledge of preventing public emergencies and the knowledge of monitoring and early warning. The prevention knowledge of public emergencies is mainly to popularize the knowledge of the publicity and prevention of public emergencies and to improve the awareness and skills of the public and organizations. Early warning knowledge is manifested as the prediction of potential event outbreak, which mainly focuses on the changes of internal and external environment and obtains the latest news about the external environment through collection, monitoring and prediction. $\mathrm{n}$ addition, the government also uses data mining and other means to analyze the existing event information, with the purpose of early detection of public emergencies and corresponding prevention and preparation. 
3) Knowledge system of emergency response: The knowledge system of emergency response mainly includes emergency command methods, rescue knowledge and emergency decision knowledge. Due to the dynamic, urgent and changeable characteristics of public emergencies, scientific and efficient emergency decision-making not only depends on the knowledge reserve before the event, but also depends on the application and innovation of knowledge when the event occurs. The government can collect data from various monitoring systems and departments. After classified statistics and situation analysis, the decisionmaking department can formulate countermeasures and rescue methods, timely issue instructions to the relevant organizations, and carry out emergency command and dispatch. The decision-making department should also effectively supervise and ensure that the instructions can be received on time and executed correctly. The establishment of information system to do a good job in the rescue work is the focus of the construction of emergency knowledge management system and will be the focus of emergency management.

4) Knowledge system of emergency assessment: After the occurrence of public emergency, the work of emergency recovery and assessment should not be neglected. The government should establish a set of performance evaluation indicators for emergency response, and conduct timely assessment on the emergency response after the occurrence of the incident. In addition, the government should analyze the emergency management process of the whole incident and draw lessons from each incident. The assessment of the incident needs to be summarized to form a set of optimization measures for the emergency management process to help further guide the practice of emergency management.

\section{COUNTERMEASURES TO IMPROVE KNOWLEDGE MANAGEMENT IN DEALING WITH PUBLIC EMERGENCIES}

\section{A. Establishing the concept of knowledge management}

In all the management, the concept should be the first, the government emergency management is no exception. Therefore, in the government emergency management, the relevant departments should change their thinking and get rid of the traditional way of data processing and information management. The government gradually accepts the concept of knowledge management, applies the concept of knowledge management to manage emergency affairs, and promotes it to become a general consensus of emergency management departments. The emergency management department fully recognizes the importance of knowledge resources and knowledge management and formulates a knowledge management strategy with a long-term perspective. When formulating knowledge management strategy, a series of problems need to be seriously considered by emergency management departments. These questions mainly include: what is the most needed knowledge of emergency management and how to obtain it, how to effectively improve the knowledge of emergency management personnel, and how to obtain useful knowledge through experts, professionals, the public and other stakeholders. The emergency management department considers how to integrate the advantages of knowledge resources into the prevention, response, handling and aftermath. The knowledge learned by the emergency management departments also includes: evaluating the effect of the utilization of knowledge resources of various departments, encouraging the innovation of knowledge in emergency management, removing various barriers to knowledge sharing among cross-departmental government organizations, and creating a cultural atmosphere conducive to knowledge dissemination.

\section{B. Building an emergency system based on knowledge management}

The government should use scientific ideas, methods and technologies to establish an emergency response system based on knowledge management on the basis of collecting and integrating related resources, and provide services for emergency management. In the prevention stage, a large number of text and non-text information and other knowledge resources need to be collected, and a deeper level of knowledge mining, in order to maximize the prevention. In the event of a public emergency, the government quickly collects all kinds of information from the scene and establishes reliable connections between experts and rescue workers. Emergency management uses a variety of tools to ensure that all departments work together to save lives and minimize damage. After the occurrence of a public emergency, the emergency management department analyzes and shares the causes and results of the incident to form new knowledge and update the knowledge base.

\section{Strengthening the promotion of knowledge management methods and tools}

First, the knowledge base should be established and updated. Through Internet information technology, a large number of existing knowledge resources can be sorted out and coded to improve the knowledge base. The government innovatively develops the emergency management knowledge resources and constantly updates the knowledge base for the convenience of users. Secondly, knowledge management tools should be used correctly. As a kind of knowledge navigation 
system, knowledge map focuses on showing the important dynamic relation between different knowledge stores. In emergency management, a complete knowledge map should consist of four types: conceptual, functional, procedural, and social. This makes it easier for decision makers and managers to search and make use of relevant knowledge, obtain the ability table of relevant personnel, and make correct decisions. If we can establish the knowledge system belonging to government departments, then the knowledge sharing and knowledge exchange ability of government workers will be most directly improved.

\section{Promoting the sharing of information and knowledge}

In the emergency management, the sharing of information and knowledge is particularly important for the realization of multi-department coordination. Therefore, it is necessary to guide emergency managers to adopt new methods and tools of knowledge management, such as knowledge communities. A knowledge community is a group of people who share a common mission or task, share common challenges and opportunities, and share a common passion for a particular topic. They share knowledge through effective collaborative tools and are committed to maximizing the value of knowledge resources within the organization. In emergency management, it is necessary to ensure that government personnel are present in one or more of the relevant emergency management knowledge communities. These communities should also be appropriately open to the public, which facilitates communication and knowledge sharing among emergency workers. The emergency response to public emergencies requires teamwork, but often results from a lack of tacit understanding. The way in which knowledge communities are constructed can largely prevent this from happening.

\section{CONCLUSION}

The introduction of knowledge management theory provides a new research idea for dealing with public emergencies. Strengthening the emergency knowledge management of public emergencies and constructing a reasonable emergency knowledge management system oriented to the emergency process can improve the decision-making level of government departments and emergency organizations in dealing with such events. Future research needs to further apply the knowledge management model, relevant technical means and software to the emergency decision-making of public emergencies, so as to improve the crisis response level of emergency management departments.

\section{References}

[1] Wang H. Overview of emergency management knowledge [J]. China electric power education, vol.29,pp.17-19,December 2013.

[2] Chen X L, Dong E C, Wang Y Z, XiaoW H. Knowledge metamodel for emergency management of irregular emergencies [J] Information journal, vol.30,pp. 22-26,December 2011

[3] Pu P G, Lu W, Liu J. Research on benefit distribution of knowledge alliance of project emergency [J]. Journal of systems engineering, vol.29,pp.138-146,Aprirl 2013.

[4] Cai F L, Chen X, Xue L. Virtual case study of emergency based on ontology and knowledge reasoning [J]. Journal of huazhong university of science and technology: natural science, vol.43,pp.93-96, October 2015.

[5] Ma X F, Zhong Q Y, Qu Y. Method for determining critical attributes of emergencies based on general knowledge model and euclidian distance [J]. Systems engineering, vol.31,pp.9397, October 2013.

[6] Wen Z Q, Tong D L, Hao Y L.analysis of knowledge map and hot topics of emergency response research from the perspective of metrology $[\mathrm{J}]$. Mathematical practice and understanding, vol.47,pp.92-104,September 2017.

[7] Cai M, Cao J. Fuzzy case-based reasoning emergency decision method for irregular emergencies from the perspective of knowledge management [J]. Soft science, vol.29,pp.139143,September 2015

[8] Li F, Wang $\mathrm{H}$ M. Research on the evolution risk of unconventional sudden flood events based on knowledge element $[\mathrm{J}]$. Systems engineering theory and practice, vol.36,pp.3255-3264, December 2016.

[9] Zhang L, Wang Y Z, Chen X L. Fuzzy inference method for irregular emergency scenarios based on knowledge element [J]. Journal of systems engineering, vol.32,pp.729-738, June 2016.

[10] Zhong Q Y, Guo Y M, Wang Ning. Study on scenario model of unconventional emergency based on knowledge element [J]. Information science, vol.30,pp.115-120, January 2012.

[11] Lu X L, Yu H F. Analysis of emergency risk based on knowledge element $[\mathrm{J}]$. China management science, vol.31,pp.108-114,August 2014.

[12] Wang N, Lu G C, Zhang K. Chain reaction path reasoning method based on knowledge element $[\mathrm{J}]$. Systems engineering, vol.36,pp.121-128, May 2016.

[13] Zhang C W, Li J W, Chen X L. Emergency scenario modeling based on knowledge element $[\mathrm{J}]$. Intelligence journal, vol.32,pp.15-19, August 2013.

[14] Zhong Q Y, Lu G, Wang N. Emergency simulation method based on knowledge element model and system dynamics model [J]. Information science, vol.32,pp.15-19, October 2014.

[15] Yang D K, Wang X H, QiuJ N. Combined call of emergency model based on knowledge element network [J]. Systems engineering, vol.28,pp.87-93,September 2012.

[16] Chen X L, Xiao W H. Knowledge element network model and its application for evolution analysis of irregular emergencies [J]. Journal of dalian university of technology, vol.64,pp.615624,April 2013.

[17] Li Y, Shan S Q, Li H. Empirical study on knowledge sharing in virtual communities for emergencies [J]. Management review, vol.24,pp.89-98,November 2012.

[18] Zeng Z M, Huang C G. Research on knowledge management system of public health emergencies from the perspective of life cycle [J]. Modern intelligence, vol.38,pp.25-29, October 2017.

[19] Jiang X, Xu X K, Tang M W. Research on the knowledge representation model for adapting to the evolution of emergencies [J]. Intelligence theory and practice, vol.39,pp.122 124, March 2016. 
[20] Shi J, Ding S R. Research on the dissemination channels of health knowledge in public health emergencies [J]. China health education, vol.23,pp.89-91, February 2007.

[21] Zhou Y M. dynamic and open framework design of ontological knowledge management of emergencies [J]. Software guide, vol.17,pp.57-61, June 2018.

[22] Li M. Factors influencing the credibility of knowledge in virtual q\&a communities in the context of emergencies [J]. Information theory and practice, vol.42,pp.128-133, September 2012.

[23] He L, Lu B Y. Study on decision-making situation and knowledge supply of emergency [J]. Information theory and practice, vol.47,pp. 105-108,December 2010.

[24] Liu J C, Tang P W, Shi M. Research on hot spot and development trend of emergency management in China -visualization analysis based on knowledge map [J]. Journal of north China university of science and technology, vol.16,pp.114-120, February 2012.

[25] Feng J, Shang L. Investigation and analysis of public health emergency knowledge of medical staff [J]. Journal of hospital management, vol.11,pp.457-458, May 2004.

[26] Wu W Yin Z H, Guan P. A survey on the knowledge of medical students responding to public health emergencies [J]. China higher medical education, vol.30,pp.3-5,November 2015. 